\title{
A aplicação da progressividade fiscal e extrafiscal no IPTU
}

\author{
Carlos Júnior Silva ${ }^{1}$ \\ Rodrigo Marcussi Fiatikoski ${ }^{2}$ \\ Tiago Octaviani ${ }^{3}$
}

\begin{abstract}
Resumo
0 presente estudo analisa os conceitos de progressividade fiscal e extrafiscal do Imposto Predial e Territorial Urbano - IPTU, destacando também os princípios que sustentam tal construção dogmática. Na primeira categoria, salienta a busca pela Justiça fiscal na atividade arrecadatória do Estado, considerando-se a capacidade contributiva de cada indivíduo. Já na modalidade extrafiscal de progressividade, destaca a preocupação com a racionalidade na ocupação do solo urbano, perquirindo-se a consagração da função social da propriedade urbana.
\end{abstract}

Palavras Chave: Alíquota; Extrafiscal; Fiscal; IPTU; Progressividade.

\section{Introdução}

O IPTU, Imposto Predial e Territorial Urbano, é o tributo que incide diretamente sobre os imóveis localizados nos limites do perímetro urbano municipal, recaindo sobre um fato permanente que pode ser periodicamente constatado. Encontra-se previsto no Art. 156, I, da Constituição Federal de 1988, inserido, portanto, no rol de impostos afetos à competência dos Municípios, in verbis:

Compete aos M unicípios instituir impostos sobre:

I - propriedade predial e territorial urbana;

[omissis]

Dentro da composição da hipótese tributária, tão bem alicerçada por Geraldo Ataliba e Paulo de Barros Carvalho, subsume-se ao critério material aquele que for proprietário de um bem imóvel, seja um terreno baldio ou uma edificação, ao passo em que, pelo critério temporal, a titularidade do bem deve se dar no primeiro dia do ano, conforme legislação do Município em questão. Já pelo critério espacial, tal imóvel deve se localizar no

\footnotetext{
${ }^{1}$ Bacharelando em Direito pela Universidade Estadual de Londrina - UEL.

2 Idem.

${ }^{3}$ Ibidem.
} 
perímetro urbano do Município, sob pena de caracterização do ITR (Imposto Territorial Rural). A definição de qual seja tal área é dada por meio do plano diretor e deve atender a, no mínimo, dois dos requisitos constantes no Art. 32, do Código Tributário Nacional:

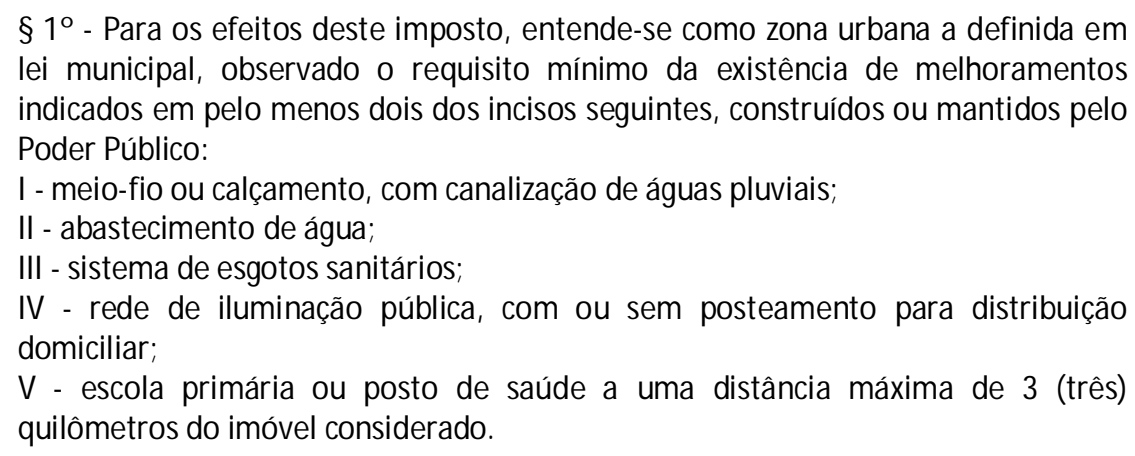
lei municipal, observado o requisito mínimo da existência de melhoramentos indicados em pelo menos dois dos incisos seguintes, construídos ou mantidos pelo Poder Público:

I - meio-fio ou calçamento, com canalização de águas pluviais;

II - abastecimento de água;

III - sistema de esgotos sanitários;

IV - rede de iluminação pública, com ou sem posteamento para distribuição domiciliar;

V - escola primária ou posto de saúde a uma distância máxima de 3 (três) quilômetros do imóvel considerado.

A sujeição ativa na relação tributária é ocupada pelo M unicípio, que tem o dever de exigir o pagamento do imposto. Já o pólo passivo é preenchido pelo contribuinte ou pelo responsável, dependendo do caso concreto. Por fim, quanto ao critério quantitativo, registre-se que a base de cálculo será o valor venal do imóvel a ser tributado, ao passo em que a alíquota dependerá de normativos municipais, podendo ser progressiva em razão de critérios fiscais ou extrafiscais, conforme mais adiante será demonstrado.

Feitas tais considerações primeiras, destaca-se que o objetivo deste estudo é demonstrar como a alíquota do IPTU pode progredir em razão da capacidade contributiva do sujeito passivo, bem como de forma a desestimular a especulação imobiliária, dando maior racionalidade ao uso do solo urbano.

\section{Dos princípios constitucionais tributários}

Dos princípios republicano e da isonomia

Conforme entende Roque Antônio Carraza, os princípios republicano e da isonomia, ambos de caráter constitucional, se completam e se interagem. É de fundamental importância a idéia de República (Art. 3ํㅡ, CF/88) no exercício da tributação para não haver injustiças e arbitrariedades, vez que deriva, em última análise, da vontade soberana do povo. Com efeito, é ele que acaba por legitimar o poder tributante do, porém sempre 0 limitando ao interesse e à manutenção da res pública (CARRAZA, 2006, p. 75-79). 
Não de outra forma, quer a Constituição Federal de 1988 que os contribuintes recebam um tratamento isonômico, é dizer, "a lei deve ser igual para todos e a todos deve ser aplicada com igualdade" (CARRAZA, 2006, p. 78), mas, além disso, deve-se buscar a satisfação da igualdade verdadeiramente material, com "um tratamento desigual aos desiguais na medida das suas desigualdades" (FURLAN, 2004, p. 119). Tal princípio basilar pode ser encontrado no Art. 150, inciso II, da CF/88, quando veda aos entes políticos:

II - instituir tratamento desigual entre contribuintes que se encontrem em situação equivalente, proibida qualquer distinção em razão de ocupação profissional ou função por eles exercida, independentemente da denominação jurídica dos rendimentos, títulos ou direitos;

Destarte, emerge como decorrência lógica dos princípios republicano e da isonomia o tão debatido primado da capacidade contributiva, efetivada por meio de impostos com alíquotas progressivas, estas destinadas a alcançarem a denominada Justiça fiscal.

Do princípio da capacidade contributiva

A Constituição Federal de 1988 adota o princípio da capacidade contributiva no Art. $145, \S 1 \underline{0}$, in verbis:

$\S 1$ - Sempre que possível, os impostos terão caráter pessoal e serão graduados segundo a capacidade econômica do contribuinte, facultado à administração tributária, especialmente para conferir efetividade a esses objetivos, identificar, respeitados os direitos individuais e nos termos da lei, o patrimônio, os rendimentos e as atividades econômicas do contribuinte.

Para Geraldo Ataliba (apud FURLAN, 2004, p. 122), a expressão capacidade econômica implica "real possibilidade de diminuir-se patrimonialmente o contribuinte, sem destruir-se e sem perder a possibilidade de persistir, gerando riqueza como lastro à tributação". Essa capacidade econômica, devidamente elencada no texto constitucional, é objetiva, e não subjetiva, vez que leva em consideração as manifestações exteriores e aferíveis de riqueza, como possuir um imóvel ou um automóvel, mormente quando se tratarem de bens de luxo ou voluptuários.

Por outras palavras, trata-se de uma presunção de riqueza, visto que a capacidade contributiva se revela já com a propriedade do referido bem (CARRAZA, 2006, p. 89-92). 
À contraio sensu, vale citar que, para Aires Fernandino Barreto e Ives Gandra da Silva Martins (2002, p. 50), a capacidade contributiva deve ser baseada em termos subjetivos, "considerando a pessoa do sujeito passivo e não o fato objetivo tributário", já que, na concepção objetiva, pode-se gerar privilégios indevidos por considerar "o valor isolado de unidades imobiliárias, que, para alguns, pode ser o único patrimônio, mas, para outros, pode ser apenas um minúsculo componente percentual".

De todo modo, como decorrência de tal princípio, caso o contribuinte venha a possuir apenas um imóvel de grande valia, entende-se que terá ele estimada capacidade contributiva, não podendo se escusar do dever de pagar o IPTU de forma progressiva sob o pretenso argumento de não possuir aptidão para suportá-lo. Aliás, com o não pagamento, 0 sujeito passivo poderá ser executado e até, eventualmente, vir a perder a propriedade do bem, nos termos da lei.

Do princípio da progressividade

De acordo com Hugo de Brito Machado (2002, p. 247-248), um tributo será progressivo quando:

[...] sua alíquota cresce, para um mesmo objeto tributado, em razão do crescimento da respectiva base de cálculo, ou de outro elemento que eventualmente 0 legislador pode eleger para esse fim. [...] a progressividade pode ser entendida como a qualidade do tributo que se eleva mais do que proporcionalmente em razão da elevação de sua base de cálculo.

Trata-se também de princípio tributário consagrado pela $\mathrm{CF} / 88$, vindo elencado no Art. 146, §1으, in verbis:

$\S 10$ - Sem prejuízo da progressividade no tempo a que se refere 0 Art. 182 , $\S 4$, inciso II, o imposto previsto no inciso I poderá:

I - ser progressivo em razão do valor do imóvel; e

II - ter alíquotas diferentes de acordo com a localização e o uso do imóvel.

Não há dúvidas de que o inciso I, ao abarcar o princípio da capacidade contributiva, o fez com caráter eminentemente fiscal, é dizer, visando à arrecadação em favor dos cofres 
do Fisco. Em contrapartida, o inciso II demonstra outra finalidade para o tributo em questão, qual seja a extrafiscalidade.

Para Carraza (2006, p. 107-108), a extrafiscalidade decorre do interesse coletivo e se verifica quando o legislador "aumenta ou diminui as alíquotas e/ou as bases de cálculo dos tributos, com o objetivo principal de induzir os contribuintes a fazer ou deixar de fazer alguma coisa". Assim, o estímulo à consecução de certas condutas é denominado extrafiscalidade favorecedora, ao passo em que o desestímulo a algum comportamento, de extrafiscalidade repressora, conforme interessante classificação defendida por Yonne Dolácio de Oliveira (apud FURLAN, 2004, p. 152-153).

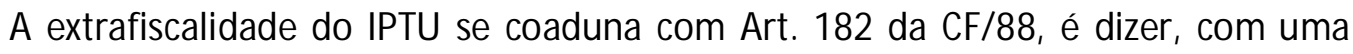
regular política de desenvolvimento urbano, podendo ser compreendida em seu $\S 4^{\circ}$, pelo qual ficou-se a progressividade no tempo, isto é, o aumento da alíquota a cada ano quando não satisfeitos os desideratos previstos no plano diretor municipal:

§ 4o - É facultado ao Poder Público municipal, mediante lei específica para área incluída no plano diretor, exigir, nos termos da lei federal, do proprietário do solo urbano não edificado, subtilizado ou não utilizado, que promova seu adequado aproveitamento, sob pena, sucessivamente, de:

I - parcelamento ou edificação compulsórios;

II - imposto sobre a propriedade predial e territorial urbana progressivo no tempo;

III - desapropriação com pagamento mediante títulos da dívida pública de emissão previamente aprovada pelo Senado Federal, com prazo de resgate de até dez anos, em parcelas anuais, iguais e sucessivas, assegurados o valor real da indenização e os juros legais.

A fim de se evitar tais sanções, deve o contribuinte assegurar que a sua propriedade urbana atende à respectiva função social (Art. 5o, inc. XXIII da CF), cabendo ao plano diretor municipal definir de que forma se dará a busca pela referida função social dos imóveis urbanos. Com efeito, tal normativo informará a pretensão urbanística para direção e planejamento de seu mapa urbano, discriminando todas as áreas destinadas à satisfação de finalidades e interesses afetos à cidade, o que proporciona desejáveis contornos de organização.

Eis então a razão pela qual João Damasceno Borges de Miranda (2002, p. 333) entende que função social se trata da busca pela destinação ocupável ao terreno, tornandoo produtivo em algo lícito, gerador de riqueza, bem como edificando-o e destinando-o ao seu correto uso. 
Com isso, a alíquota do IPTU derivará do aproveitamento racional do terreno, de acordo com o respectivo plano diretor municipal, podendo ser majorada, por exemplo, no caso de grandes prédios em bairro cuja construção de tal órbita se mostre desaconselhável por qualquer razão, o que certamente evitará edificações do tipo naquela localidade (CARRAZA 2006, p. 110).

Do princípio da não-confiscatoriedade

Seja em caso de tributação fiscal, ou em caso de extrafiscalidade, é unânime o entendimento de que a imposição tributária não pode assumir feição confiscatória. Em outros termos, as finalidades buscadas pela Administração Pública não podem gerar encargos que sejam desproporcionais aos referidos fins (FURLAN, 2004, p.149).

Com escopo constitucional no Art. 150, IV, o não-confisco deriva também do direito de propriedade elencado no Art 50, inc. XXII da CF/88. Consoante ensinamentos de Aliomar Baleeiro (apud FOLMANN, 2002, p. 501-502), tributos confiscatórios são aqueles que "absorvem parte considerável do valor da propriedade, aniquilam a empresa ou impedem 0 exercício de atividade lícita e moral". Disso se depreende que a tributação não pode atingir a um patamar tal que comprometa ou desestimule "a livre iniciativa, o trabalho e a propriedade em si, de forma não indenizável" (FOLM ANN, 2002, p. 502).

Para o Supremo Tribunal Federal, diante da falta de critérios objetivos para a aferição de tal conceito, deve 0 jurista fazer uso do princípio da razoabilidade, como condicionante da atividade estatal, de maneira a evitar a irrazoável afetação do patrimônio ou renda do contribuinte. Entende o Pretório Excelso também que deve ser levado em conta apenas a soma dos tributos exigidos pelo ente político em litígio (ALEXANDRINO; PAULO, 2007, p. 117-118).

\section{IPTU e progressividade}

Conforme se pôde depreender, o IPTU alberga duas distintas modalidades de progressividade, ambas com status constitucional: a de acordo com a capacidade contributiva do sujeito passivo (Art. 156, $\S 10$, da CF/88) e a atinente à função social da propriedade (Art. 182, §4으. II, da CF/88). A partir de tais considerações iniciais, faz-se 
conveniente adentrar em cada uma das progressividades ora elencadas, analisando-se suas notas jurídicas mais relevantes.

Da progressividade fiscal do IPTU

Ao se aplicar o princípio constitucional da isonomia ao campo do Direito Tributário, infere-se que se trata de prerrogativa do Fisco instituir tributos segundo a quantidade de riquezas que cada contribuinte vier a possuir, vez que, ao se tributar mais aquele que detém mais, alivia-se o que detém menos, em nítida consagração aos desígnios republicanos constitucionais (FURLAN, 2004, p. 121-123).

Eis a razão pela qual a CF/88 determina que, "sempre que possível, os impostos terão caráter pessoal e serão graduados segundo a capacidade econômica do contribuinte" (Art. 145, §1ํ). Noutros termos, quer a Constituição que os entes da federação estabeleçam alíquotas progressivas para fins de tributação, sempre que a realidade fático-jurídica 0 permitir.

Como desdobramento de tal preceito, há de se destacar o advento da Emenda

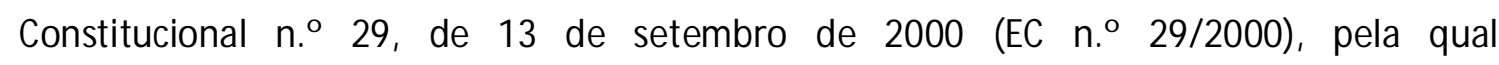
definitivamente se inseriu no ordenamento brasileiro, de forma expressa, a progressividade fiscal em razão da capacidade contributiva do sujeito passivo.

Partindo-se da premissa de que compete ao Município, detentor da titularidade do crédito tributário, bem como da qualidade de sujeito ativo da relação jurídico-tributária em matéria de IPTU, o dever de instituir, fiscalizar e arrecadar tal imposto, conclui-se que a alíquota a incidir sobre a base de cálculo (que, no caso do IPTU, se trata do valor venal do imóvel) dependerá de normas também emanadas pelo referido ente da federação.

Assim, obedecidas as devidas proporções do bom-senso, cabe ao Município fixar alíquotas progressivas em relação à respectiva base de cálculo, de forma paralelamente crescente. Vale dizer: quanto maior o valor venal do imóvel, maior será a alíquota aplicável na tributação sub examine. Isso porque, conforme defende Carraza (2006, p. 107):

[...] a só propriedade do imóvel luxuoso constitui-se numa presunção iuris et de iuri de existência de capacidade contributiva (pelo menos para fins de tributação via de IPTU). Estaria inaugurado o império da incerteza se a situação econômica individual do contribuinte tivesse que ser considerada na hora do lançamento deste imposto. 
Exemplificando-se: se um imóvel possui valor venal de $\mathrm{R} \$ 100.000,00$ (cem mil reais), incidirá alíquota, conforme legislação municipal, no importe de $0,6 \%$. Agora, se 0 imóvel, localizado nos limites territoriais do mesmo Município, vier a ser avaliado em $R \$$ $300.000,00$ (trezentos mil reais), terá então alíquota de $1 \%$. Por fim, se valer $\mathrm{R} \$ 1.000 .000,00$ (um milhão de reais), então poderá ter alíquota de 1,5\%, e assim por diante.

Disso, uma certeza se extrai: a fixação de alíquota única, não importando o valor venal do imóvel em referência, implica ofensa aos princípios constitucionais republicano, da isonomia e da capacidade contributiva, vez que, muito embora se possa alegar que a alíquota fixa também faz com que o proprietário de um imóvel melhor avaliado recolha um valor mais dilatado frente àquele que detém um imóvel mais modesto (isto em termos numéricos absolutos), o fato é que tal raciocínio não sobrevive quando invocados os mandamentos constitucionais insertos no Art. 145, §1ㅇ, e Art. 156, §1으, I.

Em outros termos, quis a Carta M agna que o mais abastado pagasse mais não só em razão da maior base de cálculo, mas também segundo uma alíquota crescente. É este também o entendimento de Carraza (2006, p. 87-88):

\begin{abstract}
Lembramos, de passagem, que a progressividade não se confunde com a proporcionalidade. Esta atrita com o princípio da capacidade contributiva, porque faz com que pessoas economicamente fracas e pessoas economicamente fortes paguem impostos com as mesmas alíquotas. É claro que, se a base de cálculo do imposto a ser pago pelo economicamente mais forte for maior do que a base de cálculo do imposto a ser pago pelo economicamente mais fraco, o quantum debeatur do primeiro será maior. Mas isto desatende ao princípio da capacidade contributiva, porque ambos estão pagando, em proporção, o mesmo imposto. Não se está levando em conta a capacidade econômica de cada qual. Na tentativa de nos fazermos entender melhor, figuremos o seguinte exemplo: se alguém ganha 10 e paga 1, outrem ganha 100 e paga 10, ambos estão pagando, proporcionalmente, o mesmo tributo ( $10 \%$ da base de cálculo). Apenas, o sacrifício econômico do primeiro é incontendivelmente maior. De fato, para quem ganha 10, dispor de 1 encerra muito maiores ônus econômicos do que para quem ganha 100 dispor de 10. 0 princípio da capacidade contributiva só será atendido se 0 imposto for progressivo, de tal arte que, por exemplo, quem ganha 10 pague 1, e quem ganha 100 pague 25.
\end{abstract}

E tal sistemática, ainda no entender do referido autor, objetiva sobretudo a tão sonhada Justiça fiscal, corolário do nosso consagrado princípio republicano (CARRAZA, 2006, pp. 86). 
Da problemática da aplicação temporal da progressividade fiscal do IPTU

A progressividade fiscal do IPTU não existia no texto original da Constituição Federal de 1988, ao menos de forma expressa. Foi só com o advento EC $n .-0$ 29/2000, ou seja, obra do Poder Constituinte derivado (reformador), cujo processo legislativo para alteração do Texto Constitucional obedece aos ditames do Art. $60, \mathrm{da} \mathrm{CF} / 88$, que se inseriu tal comando normativo no Carta Suprema brasileira.

A jurisprudência, acompanhada de parte da doutrina, já formou entendimento no sentido de que, somente após a vigência de tal Emenda, é que poderá o Fisco municipal exigir a progressividade segundo a capacidade econômica do contribuinte, mesmo diante da

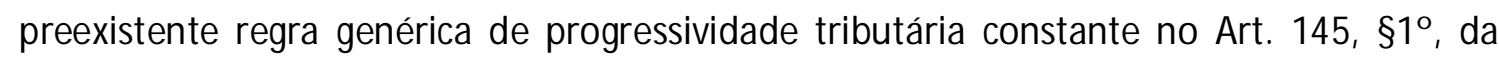
$\mathrm{CF} / 88$.

Já em sentido contrário, consigne-se os válidos argumentos trazidos por Valéria Furlan (2004, p. 139-140):

[...] queremos enfatizar que a progressividade fiscal do IPTU sempre nos pareceu perfeitamente admitida e, até mesmo, implicitamente exigida pela nossa Carta Republicana. Com efeito, diante de duas interpretações possíveis, afigura-se melhor aquela que não excepciona os princípios constitucionais. Assim, rechaçamos a interpretação que restringe demasiadamente 0 alcance do princípio da capacidade contributiva, e conseqüentemente $o$ da isonomia, no que concerne aos impostos reais.

Mas não é esta, entretanto, a posição já pacificada no Supremo Tribunal Federal acerca da problemática. 0 Pretório Excelso já firmou entendimento no sentido de ser inconstitucional a pretensão tributante do Fisco municipal segundo a sistemática da progressividade fiscal, aferível pela capacidade contributiva do sujeito passivo, para os eventos tributários verificados antes do advento da EC n.․29/2000.

Ocorre que, mesmo antes do advento de tal Emenda, diversas leis municipais não hesitaram em autorizar a Fazenda municipal a instituir e cobrar o IPTU mediante alíquotas progressivas, de acordo com a capacidade econômica do sujeito passivo, externalizada pelo valor venal do imóvel (base de cálculo).

Há exemplos também de Municípios que vêm cobrando o IPTU progressivo embasado no Art. 156, §1ํ, da CF/88, com lançamentos efetuados em data posterior à EC 
n. 29/2000, porém referentes a eventos tributários que se consumaram em período anterior à dita alteração constitucional.

A problemática, cujo caráter é nitidamente constitucional, vem sendo objeto de reiterados julgamentos no STF, conforme pode se depreender:

"EMENTA: CONSTITUCIONAL. TRIBUTÁRIO. IPTU DO MUNICÍPIO DO RIO DE JANEIRO. PROGRESSIVIDADE ANTERIOR À EC 29/2000. TAXA DE COLETA DE LIXO E LIM PEZA PÚBLICA - TCLLP. EFEITOS DA DECLARAÇÃO DE INCONSTITUCIONALIDADE NO CONTROLE DIFUSO. AGRAVO IMPROVIDO. I - A jurisprudência do Supremo Tribunal Federal é no sentido de que é inconstitucional a lei municipal que tenha estabelecido, antes da Emenda Constitucional 29/2000, alíquotas progressivas para - IPTU, salvo se destinadas a assegurar o cumprimento da função social da propriedade urbana (Súmula 668 do STF). [...]. IV - Agravo improvido." (STF AG.REG. no RECURSO EXTRAORDINÁRIO n. $380427 /$ RJ. Relator: Min. RICARDO LEWANDOWSKI. Órgão Julgador: Primeira Turma. Data da Publicação: 22-06-2007. Fonte: DJ, p. 43)

"EMENTA: 1. IPTU: progressividade: L. 5.641/89 do Município do Belo Horizonte: 0 STF firmou o entendimento - a partir do julgamento do RE 153.771, Pleno, 20.11.96, Moreira Alves - de que a única hipótese na qual a Constituição - antes da EC 29/00 - admitia a progressividade das alíquotas do IPTU era a do art. 182, § 40, II, destinada a assegurar o cumprimento da função social da propriedade urbana. 2. Progressividade: declaração de inconstitucionalidade: inviabilidade da concessão de efeitos ex nunc, no caso: precedentes.[...]." (STF - AG.REG. no AGRAVO DE INSTRUMENTO n.ㅇ 486301/MG. Relator: Min. SEPÚLVEDA PERTENCE. Órgão Julgador: Primeira Turma. Data da Publicação: 16-02-2007. Fonte: DJ, p. 30)

Tal posicionamento, diante de reiterados pronunciamentos análogos do STF, chegou a ser objeto de Súmula, in verbis:

Súmula 668 do STF: É inconstitucional a lei municipal que tenha estabelecido, antes da Emenda Constitucional 29/2000, alíquotas progressivas para o IPTU, salvo se destinada a assegurar o cumprimento da função social da propriedade urbana.

Entende a Corte Suprema que, não obstante a interpretação constitucional teleológica acerca da progressividade dos tributos, traçada como regra geral, não pode o Fisco municipal exigir valores não expressamente autorizados pelo Texto Maior, além de que impostos de natureza real (como é o caso do IPTU, vez que deriva de direito reais; direito das coisas), não comportam a progressividade prevista no Art. 145, §1ํㅡ, da CF/88, mas tão somente se e quando a própria letra da Constituição determinar, o que, no caso em apreço, só se deu após a EC n.ำ29/2000. 


\section{Da progressividade extrafiscal do IPTU}

Conforme visto, a progressividade extrafiscal do IPTU vem elencada no Art. 182, $\S 4^{\circ}$, II, da CF/88, sendo absolutamente dependente da edição do plano diretor do respectivo M unicípio, no qual serão fixados os desideratos urbanos desejados pela cidade, sendo o IPTU uma importante ferramenta para tal consecução.

Isto porque a progressividade extrafiscal busca favorecer a função social da propriedade urbana, tributando-se de forma mais acentuada os proprietários que não procedem à correta destinação de seus imóveis. Verifica-se, pois, que a função precípua de tal sistemática não reside na arrecadação de fundos ao erário público, mas sim na consecução indireta de determinado interesse público, que, no presente caso, se trata do correto uso e gozo da propriedade territorial urbana.

Por meio de tal sistemática, procura-se reprimir ou favorecer determinadas condutas humanas em relação às respectivas propriedades urbanas, de acordo com o que estabelece 0 plano diretor do Município. Diversos critérios poderão ser levados em conta para a aplicação de alíquotas progressivas, tais como: o tempo de propriedade inativa (especulação imobiliária), o espaço (exato local onde se localiza o terreno), a superfície (metragem bruta do terreno), a destinação do imóvel (residencial, comercial ou industrial), a existência de construções (edificações), dentre outros (FURLAN, 2004, p. 154-158). É esta também a posição já acolhida pelo Supremo Tribunal Federal, in verbis:

EMENTA: AGRAVO REGIMENTAL NO RECURSO EXTRAORDINÁRIO. CONSTITUCIONAL. TRIBUTÁRIO. IPTU. DIVERSIDADE DE ALÍQUOTAS. PROGRESSIVIDADE. ALEGAÇÃO IM PROCEDENTE. Diversidade de alíquotas para a cobrança do IPTU, em virtude de tratar-se de imóvel edificado, não-edificado, residencial ou comercial. Progressividade de tributo. Alegação improcedente. Precedente. Agravo regimental não provido. (STF - AG.REG.NO RECURSO EXTRAORDINÁRIO n. 432989/MG. Relator: Min. EROS GRAU. Órgão Julgador: Segunda Turma. Data da Publicação: 05-05-2006. Fonte: DJ, p. 37)

A partir de tal premissa, importante ressalva de Valéria Furlan, notória estudiosa em matéria de IPTU, merece ser transcrita (2004, p. 149):

Neste passo, convém salientar que, quer se trate de tributação fiscal, quer se trate de tributação extrafiscal, a imposição tributária não pode assumir feição confiscatória. 
Noutros termos: quaisquer que sejam as finalidades buscadas mediante a instituição de impostos, não poderá esta acarretar encargos tão acentuados que se revelem desproporcionais ao atingimento dos referidos fins.

Há, todavia, enorme dificuldade em precisar quando a tributação passa a ser desproporcional aos objetivos visados, uma vez que não há no texto constitucional uma limitação rigorosamente traçada para permitir o pronto reconhecimento desses questionados efeitos confiscatórios.

Não pode o princípio da capacidade contributiva servir-se de desculpas à ilegítima pretensão confiscatória em face do contribuinte. Em casos extremos, caberá ao Judiciário dirimir questões divergentes e até rechaçar do ordenamento eventuais normas inconstitucionais. Como exemplo de tal atividade corretiva do Judiciário, cite-se a edição da Súmula n.ำ 589, do STF, que proibiu definitivamente a progressividade em razão do número de imóveis urbanos pertencentes a um mesmo sujeito passivo. Observe-se:

Súmula 589 do STF: É inconstitucional a fixação de adicional progressivo do imposto predial e territorial urbano em função do número de imóveis do contribuinte.

Por fim, consigne-se que, embora dotado de caráter diferenciadamente extrafiscal, a progressividade contida no Art. 182, $\S 4^{\circ}$, II, da CF/88 não se distancia dos princípios constitucionais reservados àquela de caráter fiscal, mormente o da isonomia. Vale dizer, ainda que se queira favorecer determinado interesse público, não pode a tributação se revestir de arbitrariedades ou afrontar os desígnios constitucionais, sob pena de intervenção do Judiciário.

\section{Conclusão}

Conforme exposto, o atual sistema constitucional pátrio confere ao IPTU duas distintas modalidades de progressividade, quais sejam, a fiscal e a extrafiscal.

Enquanto que a primeira visa primordialmente à arrecadação com Justiça fiscal, pautada nos princípios de índole republicana, a segunda pretende garantir o bom uso da propriedade urbana, conforme disciplinar o respectivo plano diretor municipal.

Cada qual alojada em seus correspondentes desideratos, as progressividades atinentes ao IPTU representam uma distinta forma de se tributar com eficiência e racionalidade, o que as fazem ser merecedoras de aplausos por parte dos juristas. 


\section{Referências}

ALEXANDRINO, Marcelo; PAULO, Vicente. Direito Tributário na Constituição e no STF: teoria e jurisprudência. 12. Ed. Rio de Janeiro: Impetus, 2007.

BALEEIRO, Aliomar. Direito Tributário Brasileiro. 11. Ed. Rio de Janeiro: Forense, 1999.

BARBON. Sandra A. Lopez. Do IPTU. Belo Horizonte: Del Rey, 1995.

BARBOSA, Evandro Paes. Progressividade do IPTU. 1. ed. São Paulo: Editora Pillares, 2007.

BARRETO, Aires Fernandino; M ARTINS, Ives Gandra da Silva. A Inconstitucionalidade da Progressividade Prevista na EC n 29/2000. In: PEIXOTO, M arcelo M agalhães et al. IPTU: Aspectos Jurídicos Relevantes. São Paulo: Quartier Latin, 2002.

BECKER, Alfredo Augusto. Teoria Geral do Direito Tributário. 3. ed. São Paulo: Lejus, 1998.

CARRAZA, Elizabeth Nazar. IPTU e Progressividade, Igualdade e Capacidade Contributiva. Curitiba: Juruá, 2000.

CARRAZA, Roque Antônio. Curso de Direito Tributário. São Paulo: M alheiros, 2006.

CARVALHO, Paulo de Barros. Curso de Direito Tributário. 18. ed. São Paulo: Saraiva, 2007.

CONTI, José M aurício. Princípios Tributários da Capacidade Contributiva e da Progressividade. São Paulo: Dialética, 1997.

FOLM ANN, M elissa. IPTU e Tributação Ambiental. In: PEIXOTO, M arcelo M agalhães et al. IPTU: aspectos jurídicos relevantes. São Paulo: Quartier Latin, 2002.

FURLAN, Valéria. Imposto Predial e Territorial Urbano. 2. ed. São Paulo: Malheiros Editores, 2004.

M ACHADO, Hugo de Brito. Curso de Direito Tributário. 27. ed. São Paulo: M alheiros Editores, 2006.

M ACHADO, Hugo de Brito. Progressividade e Seletividade no IPTU. In: PEIXOTO, Marcelo Magalhães et al. IPTU: aspectos jurídicos relevantes. São Paulo: Quartier Latin, 2002.

M ARTINS, Ives Gandra da Silva et al. Curso de Direito Tributário. 8. ed. São Paulo: Saraiva, 2001.

M IRANDA, João Damasceno Borges de. A Regra-M atriz do IPTU e sua Constitucionalidade. In: PEIXOTO, M arcelo Magalhães et al. IPTU: aspectos jurídicos relevantes. São Paulo: Quartier Latin, 2002. 
M ORAES, Alexandre. Direito Constitucional. 10. ed. São Paulo: Atlas, 2001.

PAULSEN, Leandro. Direito Tributário: Constituição Federal e Código Tributário à luz da Doutrina e Jurisprudência. 9. ed. Porto Alegre: Livraria do Advogado, 2007. 